\title{
Distribution and spatial autocorrelation of the hospitalizations for cardiovascular diseases in adults in Brazil
}

\author{
Distribuição e autocorrelação espacial das internações por \\ doenças cardiovasculares em adultos no Brasil \\ Distribución y autocorrección de espacios en las admisiones de \\ enfermedades cardiovasculares en adultos en Brasil \\ Fernanda Sabini Faix Figueiredo $o^{a, b}$ \\ Thamires Fernandes Cardoso da Silva Rodrigues ${ }^{a}$ \\ Anderson da Silva Rêgo ${ }^{a}$ \\ Luciano de Andrade \\ Rosana Rosseto de Oliveira ${ }^{a}$ \\ Cremilde Aparecida Trindade Radovanovic ${ }^{a}$
}

\section{How to cite this article:} Figueiredo FSF, Rodrigues TFCS, Rêgo AS, Andrade L, Oliveira RR, Rodavanovic CAT. Distribution and spatial autocorrelation of the hospitalizations for cardiovascular diseases in adults in Brazil. Rev Gaúcha Enferm. 2020;41:e20190314 doi: https://doi.org/10.1590/19831447.2020 .20190314

\footnotetext{
Universidade Estadual de Maringá (UEM), Departamento de Enfermagem, Programa de Pós-graduação em Enfermagem. Maringá, Paraná, Brasil.

¿ Prefeitura Municipal de Ponta Grossa. Estratégia Saúde da Família. Ponta Grossa, Paraná, Brasil.
}

\section{ABSTRACT}

Objectives: To analyze the distribution and spatial autocorrelation of the hospitalization rates for cardiovascular diseases in adults, and to verify the correlation with socioeconomic and health factors in Brazil.

Methods: An ecological study of hospitalization rates for cardiovascular diseases in adults from 2005 to 2016. Spatial dependence was analyzed by the Moran Global and Local autocorrelation coefficients. The correlation between hospitalization rates and socioeconomic and health variables was calculated using the Spearman's correlation coefficient.

Results: The highest hospitalization rates were observed in the states of Santa Catarina, Paraná, São Paulo, and Mato Grosso, with high-high autocorrelation clusters for ischemic heart disease. The hospitalizations for cardiovascular diseases were strongly correlated with low schooling, alcohol consumption, and diagnosis of hypertension.

Conclusion: The high rates of hospitalization in the states mentioned, linked to socioeconomic and health factors, suggest public policies focused on the theme.

Keywords: Cardiovascular diseases. Spatial analysis. Adult health. Hospitalization. Public health nursing. Epidemiological monitoring. RESUMO

Objetivos: Analisar a distribuição e autocorrelação espacial das taxas de internação por doenças cardiovasculares em adultos, e verificar a correlação com fatores socioeconômicos e de saúde no Brasil.

Métodos: Estudo ecológico das taxas de internação por doenças cardiovasculares em adultos no período de 2005 a 2016. A dependência espacial foi analisada pelo coeficiente de autocorrelação de Moran Global e Local. A correlação entre taxas de internação e variáveis socioeconômicas e de saúde foi calculada por meio do coeficiente de correlação de Spearman.

Resultados: As maiores taxas de internações foram observadas nos estados de Santa Catarina, Paraná, São Paulo e Mato Grosso, com conglomerados da autocorrelação do tipo alto-alto para doenças isquêmicas do coração. As internações por doenças cardiovasculares apresentaram correlação forte com baixa escolaridade, consumo de álcool e diagnóstico de hipertensão arterial.

Conclusão: As altas taxas de internação nos estados citados, atrelados a fatores socioeconômicos e de saúde sugerem a necessidade de políticas públicas focados na temática.

Palavras-chave: Doenças cardiovasculares. Análise espacial. Saúde do adulto. Hospitalização.Enfermagem em saúde pública. Monitoramento epidemiológico.

\section{RESUMEN}

Objetivos: Analizar la distribución y autocorrelación espacial de los índices de internación por enfermedades cardiovasculares en adultos, y verificar la correlación con los factores socioeconómicos y de salud en Brasil.

Métodos: Estudio ecológico de índices de internación por enfermedades cardiovasculares en adultos de 2005 a 2016. La dependencia espacial se analizó mediante el coeficiente de autocorrelación global y local de Moran. La correlación entre los índices de internación y las variables socioeconómicas y de salud se calculó utilizando el coeficiente de correlación de Spearman.

Resultados: Los índices de internación más elevados se observaron en los estados de Santa Catarina, Paraná, São Paulo y Mato Grosso, con conglomerados de autocorrelación de alta para la cardiopatía isquémica. Las internaciones por enfermedades cardiovasculares se correlacionaron fuertemente con la baja educación, el consumo de alcohol y el diagnóstico de hipertensión.

Conclusión: Los elevados índices de internación en los estados mencionados, vinculados a factores socioeconómicos y de salud, sugieren políticas públicas centradas en el tema.

Palabras clave: Enfermedades cardiovasculares. Análisis espacial. Salud del adulto. Internación. Enfermería en salud pública. Monitoreo epidemiológico. 


\section{口INTRODUCTION}

Cardiovascular Diseases (CVDs) refer to a group of morbidities involving the heart and blood vessels, or even sequelae arising from an inadequate vascular blood supply ${ }^{(1)}$. Currently, they occupy the fourth position in the causes of hospitalization, being the first cause of mortality in Brazil. In 2018,6,217,525 hospitalizations were recorded in adults aged between 20 and 59 years old and, of these, 441,725 corresponded to $\mathrm{CVDs}^{(2)}$.

The process of hospitalization of the adult and economically active population, in addition to causing emotional distress for the patient and his family, causes greater financial impacts, since it generates absence from work activities and can bring consequences with permanent and costly consequences for the families ${ }^{(2-3)}$, implying significant expenses for the health system and other segments of society the individual is a part of. Between the years 2010 and 2015, costs with CVDs increased by $17 \%$, corresponding to an approximate value of $\mathrm{R} \$ 37.1$ billion ${ }^{(4)}$.

CVDs include two groups of diseases that are more prevalent: Ischemic Heart Diseases (IHDs) and Cerebrovascular Diseases $(\mathrm{CbVDs})^{(2)}$. Both CVDs and other Chronic Non-Communicable Diseases (CNCDs) have their cause strictly associated with some risk factors, which are considered non-modifiable, such as age, gender and genetic predisposition, and modifiable referring to lifestyle, such as smoking, drinking, inadequate diet and physical inactivity ${ }^{(1,5)}$. The control of the risk factors is essential for the reducing the occurrence of CVDs, and it is in this parameter that the health professionals must join efforts, with interventions that improve quality of life and control the occurrence of this disease in the population ${ }^{(6)}$.

The mobilization of actions to combat CVDs can be made possible and effective when directed to the specific needs of each population and territory. Therefore, the verification of the occurrence of CVDs can be associated with the spatialization techniques applied to ecological data, as they allow for a diagnosis of the situation, identifying the need for planning and allocation of resources, prioritizing strategies aimed at the prevention and treatment of these diseases according to the risks evidenced in each territory ${ }^{(7)}$.

Spatial distribution studies and correlated variables promote in the health managers the need for decision making, revealing the areas that need further redirection of the system and of the health actions. It is extremely important that the health professionals know the distribution of these diseases in their areas, states and regions, and that they act in an articulated manner and promote aligned strategies for the benefit of the population's quality of life and for reducing the occurrence of cardiovascular diseases, thus reducing the hospitalization rates and the morbidity costs associated with these diseases ${ }^{(6-7)}$.

Due to the magnitude of the occurrence of circulatory system diseases, and due to the potential for morbidity and mortality and to the high costs charged on the economy, the accurate diagnosis of the spatial distribution of the hospitalizations for these diseases in Brazil, as well as the correlated factors, is necessary so that more accurate and effective interventions are implemented. Thus, the objective of this study was to analyze the distribution and spatial autocorrelation of the hospitalization rates for CVDs in adults, and to verify the correlation with socioeconomic and health factors in Brazil.

\section{METHODOLOGY}

An ecological, cross-sectional study of hospitalization rates for CVDs and its main subgroups, IHDs and CbVDs, among adults in the states of Brazil.

The hospitalization data were obtained from the Hospital Information System of the Unified Health System (Sistema de Informações Hospitalares do Sistema Único de Saúde, SIH/ SUS) by accessing the site of the Informatics Department of the SUS (DATASUS) in the "Epidemiological and morbidity"link; hospital morbidity of the SUS by place of residence. The population data was obtained on the same page by selecting the "Demographic and socioeconomic" link to obtain the projection of the population, according to the age groups and the federative units.

The calculation of hospitalization rates was carried out for three quadrennia (2005-2008, 2009-2012 and 2013-2016), with hospitalizations by the three groups of diseases: CVDs, IHDs and CbVDs. Considering the possibility of random fluctuations in the number of hospitalizations, the rates were obtained by the ratio between the sum of hospitalizations in each period and the sum of the respective population, in the same period, multiplied by 100,000.

For the analysis of spatial distribution and autocorrelation, the states were the units of spatial analysis, whose cartographic base with the limits of the states is available on the website of the Brazilian Institute of Geography and Statistics (Instituto Brasileiro de Geografia e Estatística, IBGE). The distribution of the hospitalization rates in the studied periods was demonstrated through maps with intervals between the maximum and minimum rates.

The figures were constructed using QGIS version 2.8, and the rates were represented on the map by color scales, where the darkest colors represent the locations with the highest rates and the lightest colors, the lowest rates. For the statistical analysis of the spatial dependence, Moran's 
autocorrelation coefficient was used, which is subdivided into the Moran Global and Local indexes (LISA). The results of applying the global Moran and LISA indexes evaluated hypotheses of spatial autocorrelation for hospitalizations due to CVDs in the states of Brazil.

LISA provides more detailed information on different types of associations: high-high, when the rate of hospitalizations between a state and its neighbor is high; and low-low, when it is low in both states. We can also find the outliers, when the ratio of a state is high and that of its neighbor is low; or, on the contrary, in these cases we have associations of the high-low and low-high types, respectively. States that do not have a clear spatial tendency, which have high ratios around low ratios, are classified as non-significant ${ }^{(8)}$.

The Spearman's correlation coefficient was used to verify the existence of a correlation between the rates of hospitalization for CVDs, IHDs and CbVDs in the period from 2013 to 2016 and the following socioeconomic variables: less than eight years of study, population served by sewage and water networks, Human Development Index (HDI), mean per capita income andGini's index, which measures the distribution of income (ranges from 0 to 1 , where 0 is perfect equality and 1 is maximum inequality).

The following health variables were also used: alcohol consumption one or more times a week, current cigarette smokers, users of tobacco products, high cholesterol, medical diagnosis of Systemic Arterial Hypertension ( $\mathrm{SAH}$ ), high salt consumption, and coverage of the Family Health Strategy (FHS) in the 2013-2016 period. All the data were obtained by consulting the DATASUS page, with the exception of the FHS coverage, which is made available by accessing the website of the Primary Care Department: www.dab.saude.gov.br.

The Spearman's correlation coefficients were interpreted according to the following parameters: if the correlation coefficient $<0.4$, the correlation is of low magnitude, if the correlation coefficient $\geq 0.4$ to $<0.5$, the correlation is considered to be of a moderate magnitude and, finally, correlation coefficients $\geq 0.5$ represent a correlation of a strong magnitude ${ }^{(9)}$. A significance level of $5 \%$ was considered. Version 20.0 of the Statistical Package for Social Sciences (SPSS) software was used to perform the analyses.

The Standing Committee for Ethics in Research Involving Human Beings (Comitê Permanente de Ética em Pesquisa Envolvendo Seres Humanos, COPEP) of the State University of Maringá approved the exemption of ethical analysis under opinion No. 18/2016, since the data were collected on a public domain basis, with no possibility to identify the subjects.

\section{RESULTS}

A total of 5,681,902 hospitalizations were analyzed for the age group of 20 to 59 years old, of both genders, in the period from 2005 to 2016. When analyzing the distribution of absolute and relative frequencies, and of hospitalization rates by major regions and in Brazil as a whole, it was observed that all the regions recorded a reduction in the hospitalization rates due to CVDs from the first to the last quadrennium.

The South region had the highest rates of hospitalizations for CVDs over the entire period studied, and the North region showed the lowest rates of hospitalizations. The Midwest region stood out, obtaining the greatest reduction in the hospitalization rates for CVDs. In the first study period (2005-2008), it was the second region with the highest number of hospitalizations, managing to reduce the rate from 546.44 hospitalizations per 100,000 inhabitants to 359.50 in the most recent years (Table 1).

Regarding the hospitalizations due to IHDs, there was a reduction in the hospitalization rates only in the Southeast region, from a rate of 103.23 hospitalizations in the 20052008 period to 98.03 hospitalizations per 100,000 inhabitants in 2013-2016. The hospitalizations for CbVDs showed a reduction in their rates between the periods studied, with the exception of the Northeast region, which increased, from 49.65 to 54.15 per 100,000 inhabitants. It is noteworthy that the rates of hospitalization for IHDs and CbVDs were higher in the South and lower in the North (Table 1).

When analyzing the spatial distribution of the hospitalization rates for CVDs, the states that maintained the highest rates throughout the study period were Paraná, Santa Catarina, Rio Grande do Sul, and Minas Gerais. The states of Pernambuco, Acre and Rondônia showed an increase in the hospitalization rates for CVDs. In the case of hospitalizations due to IHDs, the state of Paraná maintained higher rates throughout the analysis period, while for hospitalizations due to CbVDs this pattern occurred in the states of Rio Grande do Sul and Minas Gerais (Figure 1).

The results of the local spatial autocorrelation of the hospitalizations indicated similar patterns of states with high rates, surrounded by neighbors with high rates (highhigh), and states with low rates, surrounded by neighboring states also with low rates (low-low). The hospitalizations due to CVDs showed a low-low autocorrelation in the states of Acre, Amazonas and Roraima in the 2013-2016 period, and a high-high autocorrelation in the states of Santa Catarina, SãoPaulo, MatoGrossodoSul, and the FederalDistrict (Figure 2). 
Table 1 - Distribution of the absolute and relative frequencies, and of the hospitalizations rates for cardiovascular diseases, ischemic heart diseases and cerebrovascular diseases. Brazil, 2005-2016

\begin{tabular}{|c|c|c|c|c|c|c|c|c|c|}
\hline & \multicolumn{3}{|c|}{$2005-2008$} & \multicolumn{3}{|c|}{ 2009-2012 } & \multicolumn{3}{|c|}{ 2013-2016 } \\
\hline & $\mathbf{N}$ & $\%$ & Rate & $\mathbf{n}$ & $\%$ & Rate & $\mathbf{n}$ & $\%$ & Rate \\
\hline \multicolumn{10}{|c|}{ CVDs } \\
\hline North & 101,679 & 5.15 & 338.90 & 100,878 & 5.25 & 301.76 & 93,820 & 5.25 & 255.09 \\
\hline Northeast & 394,026 & 19.95 & 362.66 & 403,837 & 21.02 & 345.65 & 386,343 & 21.63 & 312.81 \\
\hline Southeast & 920,941 & 46.63 & 508.74 & 881,695 & 45.90 & 462.85 & 812,040 & 45.47 & 410.22 \\
\hline South & 394,018 & 19.95 & 643.89 & 387,016 & 20.15 & 600.68 & 365,108 & 20.45 & 543.85 \\
\hline Midwest & 164,365 & 8.32 & 546.44 & 147,679 & 7.69 & 447.95 & 128,457 & 7.19 & 359.50 \\
\hline Brazil & $1,975,029$ & 100.0 & 480.60 & $1,921,105$ & 100.0 & 438.45 & $1,785,768$ & 100.0 & 387.28 \\
\hline \multicolumn{10}{|c|}{ IHDs } \\
\hline North & 10,696 & 2.95 & 35.65 & 11,319 & 2.91 & 33.86 & 14,253 & 3.51 & 38.75 \\
\hline Northeast & 43,946 & 12.13 & 40.45 & 53,366 & 13.71 & 45.68 & 62,594 & 15.41 & 50.68 \\
\hline Southeast & 186,873 & 51.59 & 103.23 & 194,032 & 49.84 & 101.86 & 194,050 & 47.77 & 98.03 \\
\hline South & 96,634 & 26.68 & 157.92 & 102,929 & 26.44 & 159.75 & 106,676 & 26.26 & 158.90 \\
\hline Midwest & 24,046 & 6.64 & 79.94 & 27,700 & 7.11 & 84.02 & 28,659 & 7.05 & 80.20 \\
\hline Brazil & 362,195 & 100.0 & 88.14 & 389,346 & 100.0 & 88.86 & 406,232 & 100.0 & 88.10 \\
\hline \multicolumn{10}{|c|}{ CbVDs } \\
\hline North & 13,325 & 5.24 & 44.41 & 13,443 & 5.49 & 40.21 & 15,070 & 5.78 & 40.98 \\
\hline Northeast & 53,945 & 21.19 & 49.65 & 57,003 & 23.29 & 48.79 & 66,876 & 25.66 & 54.15 \\
\hline Southeast & 120,274 & 47.26 & 66.44 & 110,945 & 45.33 & 58.24 & 111,917 & 42.94 & 56.54 \\
\hline South & 47,870 & 18.81 & 78.23 & 45645 & 18.65 & 70.84 & 47,863 & 18.36 & 71.30 \\
\hline Midwest & 19,105 & 7.51 & 63.52 & 17,725 & 7.24 & 53.76 & 18,899 & 7.25 & 52.89 \\
\hline Brazil & 254,519 & 100.0 & 61.93 & 244,761 & 100.0 & 55.86 & 260,625 & 100.0 & 56.52 \\
\hline
\end{tabular}

Source: Research data, 2016.

CVDs: Cardiovascular Diseases; IHDs: Ischemic Heart Diseases; CbVDs: Cerebrovascular Diseases. 


\section{$2005-2008$}
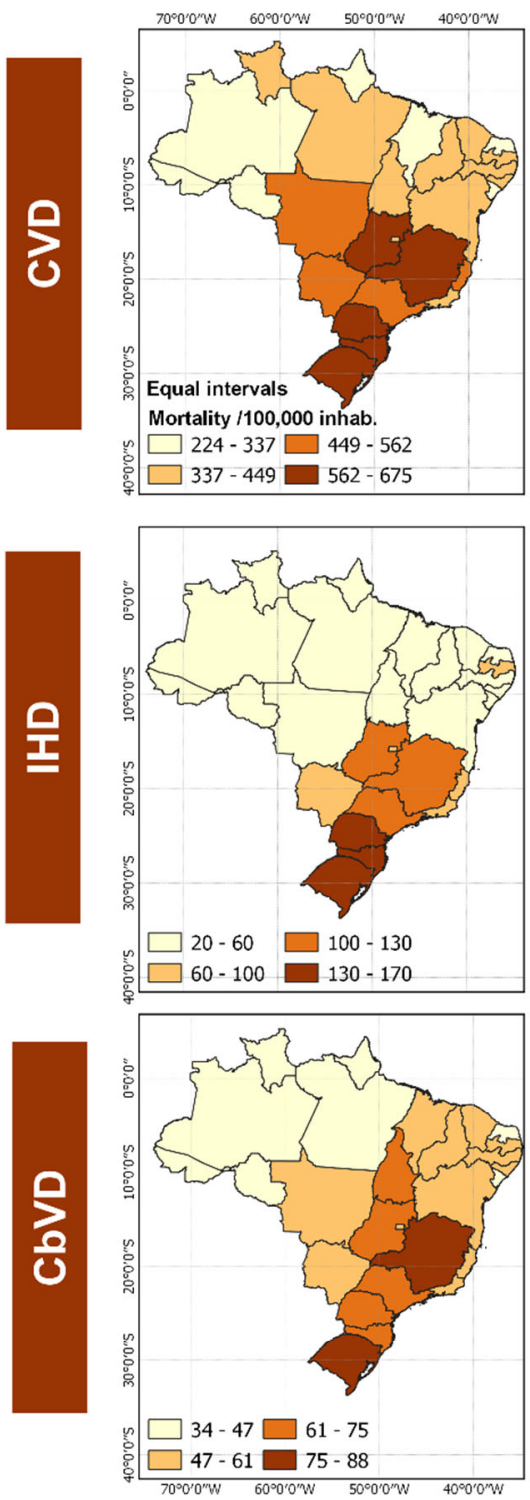

$2009-2012$
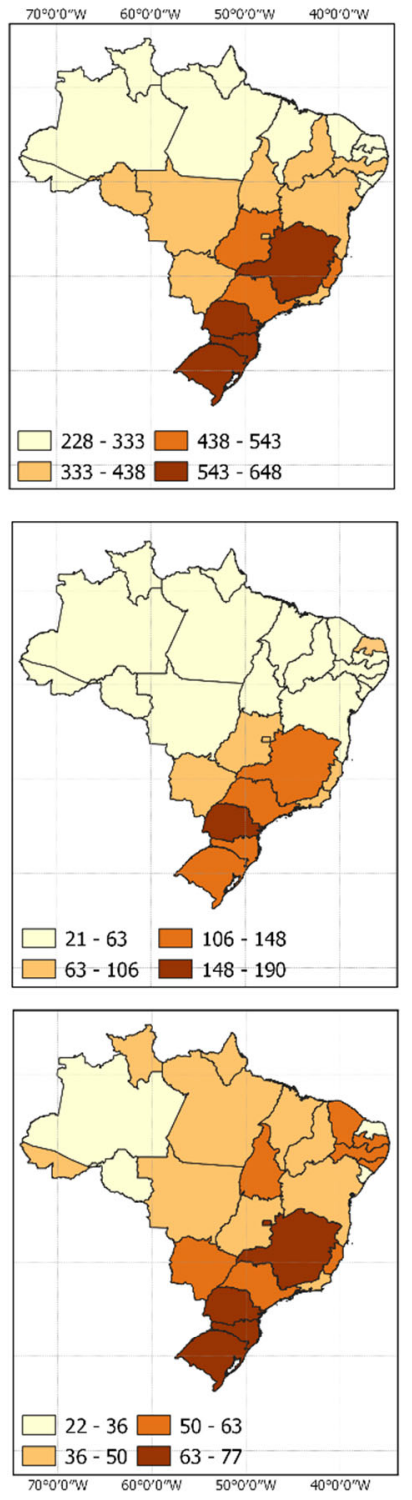

$2013-2016$
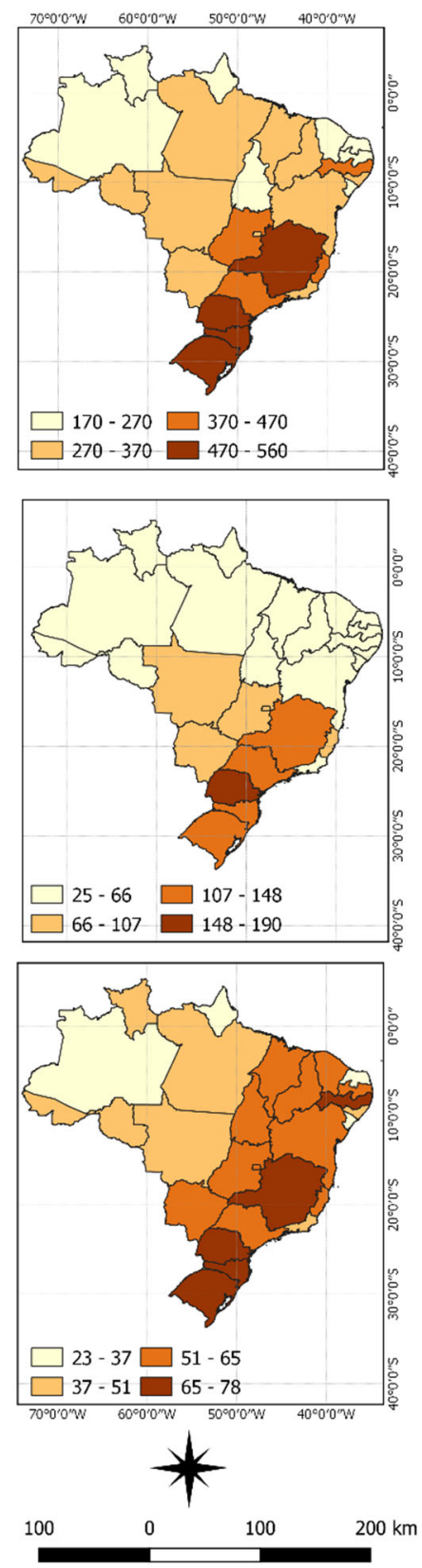

Figure 1 - Spatial distribution of the hospitalization rates for cardiovascular diseases. Brazil, 2005-2016. Source: Research data, 2016.

CVD: Cardiovascular Diseases; HHD: Ischemic Heart Diseases; CbVD: Cerebrovascular Diseases.

The hospitalizations for IHDs maintained a similar trend for the North and Northeast regions, with a low-low autocorrelation only in the cluster made up by the states of Amazonas, Pará, Tocantins, Maranhão, and Piauí in the last quadrennium. The cluster made up by states with a high-high autocorrelation for IHDs, the same during all the periods, was formed by the states of Santa Catarina, Paraná, São Paulo, and Mato Grosso do Sul. For hospitalizations due to CbVDs, in the last quadrennium, a low-low type autocorrelation is observed only in the state of Pará, and of the "high-high" 


\section{$2005-2008$}
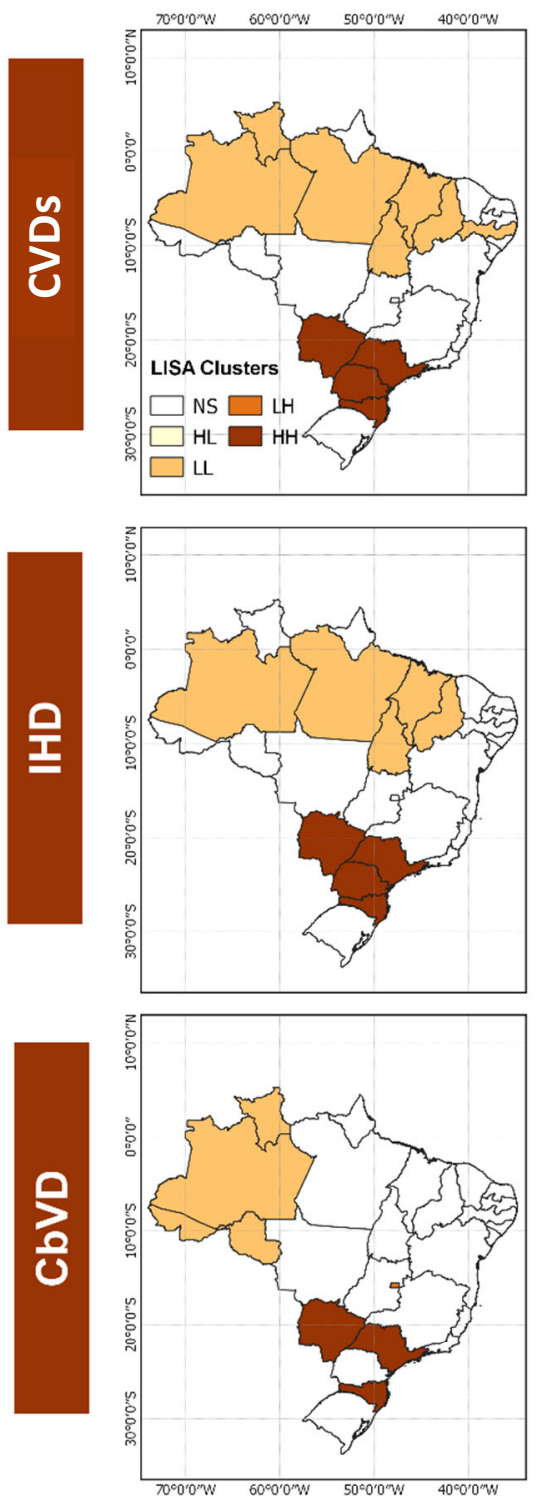
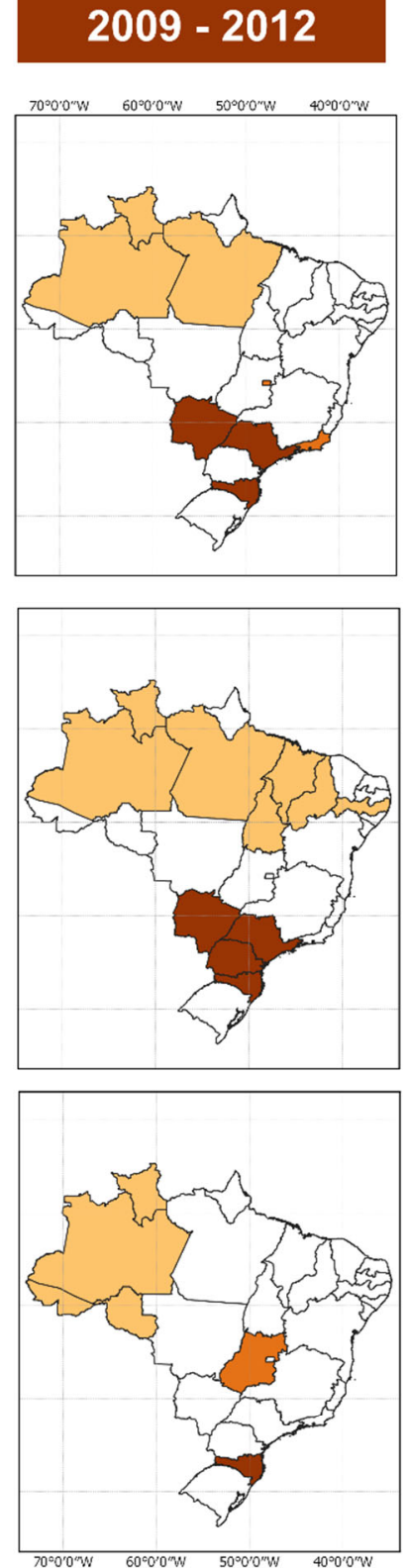

\section{$2013-2016$}
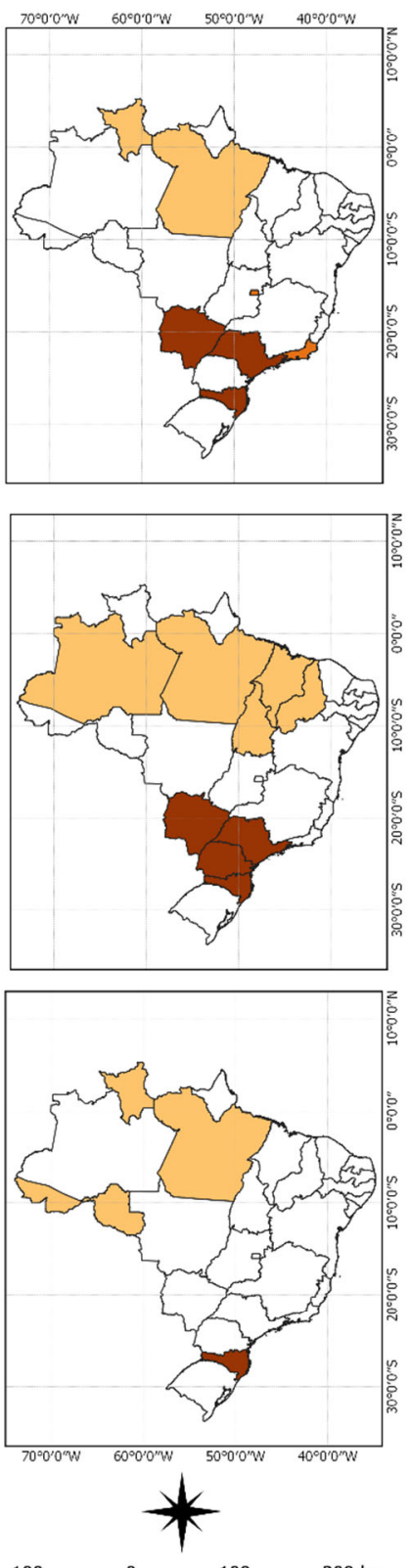

Figure 2 - Spatial autocorrelation map of the hospitalization rates for cardiovascular diseases according to the Local Moran Index (LISA). Brazil, 2005-2016 Source: Research data, 2016

CVD: Cardiovascular Diseases; IHD: Ischemic Heart Diseases; CbVD: Cerebrovascular Diseases. NS: Not Significant; HH: High-High; LL: Low-Low; LH: Low-High; HL: High-Low.

type in Santa Catarina, Paraná, Mato Grosso do Sul, the Federal District, São Paulo, and Minas Gerais (Figure 2).

The correlations between the hospitalization rates by the groups of CVDs, IHDs and CbVDs were analyzed, with the socioeconomic (Table 2) and health (Table 3) variables. In relation to the hospitalization rates due to CVDs, these showed a strong correlation with the variables of schooling level less than 8 years of study $(0.52 ; p=0.005)$, population served by sewage 
network (040; $p=0.040)$, and a negative correlation with the Gini's index ( $-0.57 ; p=<0.002)$. Of the health variables, the following had a strong correlation with CVDs: alcohol consumption $(0.53 ; p=0.005)$ and the diagnosis of SAH $(0.52 ; p=0.006)$, a moderate magnitude correlation was verified with the followingvariables: current cigarette smokers $(0.47 ; p=0.014)$, and users of tobacco products $(0.43 ; p=0.024)$.

For the hospitalizations due to IHDs, a strong correlation was verified with most of the socioeconomic variables (Table 2), with the only exception of the variable of schooling less than 8 years. The health variables that had a strong correlation with the hospitalizations were the following: diagnosis of SAH $(0.83 ; p<0.001)$ and alcohol consumption $(0.58 ; p=0.002)$.
There was also a significant correlation of a moderate magnitude in the high salt intake $(0.45 ; p=0.017)$ and high cholesterol $(0.45 ; p=0.018)$ variables (Table 3 ).

The hospitalizations for CbVDs had a strong correlation only with the health variable of alcohol consumption one or more times a week $(0.55 ; p=0.003)$. A moderate correlation was found with the use of tobacco by-products $(0.47 ; p=0.013)$, current cigarette smokers $(0.47 ; p=0.013)$ and a medical diagnosis of SAH $(0.41 ; p=0.036)$ (Table 3 ). Among the socioeconomic variables, a moderate correlation was found with less than 8 years of schooling $(0.45 ; p=0.018)$, and a moderate negative correlation with the Gini's index $(-0.44 ; p=0.022$ ) (Table 2).

Table 2 - Correlation between the hospitalization rates for cardiovascular diseases and socioeconomic variables. Brazil, $2005-2016$

\begin{tabular}{|c|c|c|c|c|c|c|}
\hline \multirow{2}{*}{$\begin{array}{l}\text { Socioeconomic } \\
\text { variables }\end{array}$} & \multicolumn{2}{|c|}{ CVDs } & \multicolumn{2}{|c|}{ IHDs } & \multicolumn{2}{|c|}{ CbVDs } \\
\hline & $\begin{array}{l}\text { Correlation } \\
\text { Coeff.* }\end{array}$ & $p$ & $\begin{array}{c}\text { Correlation } \\
\text { Coeff. }\end{array}$ & $P$ & $\begin{array}{c}\text { Correlation } \\
\text { Coeff. }\end{array}$ & $p$ \\
\hline Schooling $<8$ years & 0.52 & 0.005 & 0.36 & 0.068 & 0.45 & 0.018 \\
\hline $\begin{array}{l}\text { Population served } \\
\text { by sewage }\end{array}$ & 0.40 & 0.040 & 0.71 & $<0.001$ & 0.33 & 0.089 \\
\hline $\begin{array}{l}\text { Population served by } \\
\text { water network }\end{array}$ & 0.32 & 0.101 & 0.70 & $<0.001$ & 0.32 & 0.103 \\
\hline $\mathrm{HDS}^{* *}$ & 0.32 & 0.099 & 0.72 & $<0.001$ & 0.29 & 0.141 \\
\hline Mean per capita income & 0.33 & 0.088 & 0.72 & $<0.001$ & 0.25 & 0.209 \\
\hline Gini's Index & -0.57 & 0.002 & -0.72 & $<0.001$ & -0.44 & 0.022 \\
\hline
\end{tabular}

Source: Research data, 2016

CVDs: Cardiovascular Diseases; IHDs: Ischemic Heart Diseases; CbVDs: Cerebrovascular Diseases. * Spearman's correlation coefficient. **Human Development Index.

Table 3 - Correlation between the hospitalization rates for cardiovascular diseases and health variables. Brazil, $2005-2016$

\begin{tabular}{lcccccc} 
& \multicolumn{2}{c}{ CVDs } & \multicolumn{2}{c}{ IHDs } & \multicolumn{2}{c}{ CbVDs } \\
\cline { 2 - 7 } Health variables & $\begin{array}{c}\text { Correlation } \\
\text { Coeff** }\end{array}$ & $\boldsymbol{p}$ & $\begin{array}{c}\text { Correlation } \\
\text { Coeff** }\end{array}$ & $\boldsymbol{P}$ & $\begin{array}{c}\text { Correlation } \\
\text { Coeff.* }\end{array}$ & $\boldsymbol{p}$ \\
\hline Alcohol consumption $\geq 1$ 1x in the week & 0.53 & 0.005 & 0.58 & 0.002 & 0.55 & 0.003 \\
Smokers & 0.47 & 0.014 & 0.18 & 0.366 & 0.47 & 0.013 \\
Users of tobacco by-products & 0.43 & 0.024 & 0.14 & 0.473 & 0.47 & 0.013 \\
High cholesterol & 0.23 & 0.240 & 0.45 & 0.018 & 0.28 & 0.155 \\
Medical diagnosis of SAH** & 0.52 & 0.006 & 0.83 & $<0.001$ & 0.41 & 0.036 \\
High consumption of salt & 0.31 & 0.110 & 0.45 & 0.017 & 0.16 & 0.420 \\
FHS Coverage*** 2013-2016 & -0.27 & 0.165 & -0.34 & 0.082 & -0.15 & 0.464 \\
\hline
\end{tabular}

Source: Research data, 2016

Coeff: Coefficient; CVDs: Cardiovascular Diseases; IHDs: Ischemic Heart Diseases; CbVDs: Cerebrovascular Diseases. ${ }^{*}$ Spearman's correlation coefficient. ${ }^{* *}$ Systemic Arterial Hypertension. ${ }^{* * *}$ Family Health Strategy. 


\section{DISCUSSION}

The results of this study show that there are important differences between the distribution of the hospitalization rates for CVDs in the states of Brazil. It is possible to identify similarities between neighboring states, and through spatial autocorrelation. It is verified with greater precision that, in current years, the states of Santa Catarina, Paraná, São Paulo, Minas Gerais, and Mato Grosso do Sul, make up a cluster of the high-high type for the rates of hospitalizations due to CbVDs and also for IHDs, with the exception of the state of Minas Gerais.

Over the twelve years surveyed, Paraná, Santa Catarina, Rio Grande do Sul and Minas Gerais were the states with the highest rates of hospitalization for CVDs, a fact that can be justified by the Southeast and South regions having the highest rates of individuals with hypertension in the country ( $23.3 \%$ and $22.9 \%$ respectively), while the lowest index $(14.5 \%)^{(10)}$ is concentrated in the North region. SAH is considered to be the most important cardiovascular risk factor, as it is associated with the development of chronic kidney disease, stroke, Acute Myocardial Infarction(AMI) and coronary artery diseases, in addition to a direct association with cardiovascular and renal morbidity and mortality ${ }^{(11)}$.

A study conducted in the state of São Paulo ${ }^{(12)}$ pointed out the presence of spatial correlation for arterial hypertension, reinforcing the need to improve the diagnosis and treatment of the morbidity in younger individuals. For not having policies specifically geared to this age group, the adult public is most often the one charged with the tasks of work, with little time dedicated to consultations and preventive activities ${ }^{(12)}$.

In addition, a spatial study conducted in South Korea also found a strong spatial correlation with hypertension, linked to socio-demographic and economic indicators ${ }^{(13)}$. Thus, it is suggested that the population of the Southeast and South regions have better access to diagnostic tests and also to medications since, in these regions, the largest number of people is concentrated who report having had tests such as total cholesterol, triglycerides, serum analysis of glucose, and that refer to the use of antihypertensive medications ${ }^{(11)}$.

In addition to the South and Southeast concentrating the highest number of hypertensive individuals, and to the fact that the present study revealed a strong correlation between the rates of hospitalizations for CVDs and SAH, another assumption for the high rates, especially in the South region, is the rate of beds per inhabitant, where such index in the South is estimated to be higher. In this perspective, a study carried out in the Brazilian micro-regions also showed a strong spatial correlation with hospitalizations due to CVDs, exacerbated by sociodemographic and economic variables, especially in states in the South and Southeast region ${ }^{(14)}$.

A research study identified that there is evidence that the CVDs are more marked in people with less schooling ${ }^{(15)}$, which is also verified by the correlation analysis, where the rates of hospitalizations for CVDs showed a strong correlation with individuals with less than eight years of study. It can be assumed that a higher level of education is an important factor for self-care with health, and that it can also favor the search for better conditions and quality of life.

IHDs had a strong correlation with the mean per capita income. The highest prevalence of CVDs is commonly found in people with lower socioeconomic status ${ }^{(15)}$; however, only hospitalizations for IHDs showed this correlation. Particularly, IHDs have more risk factors involved and their diagnosis often depends on more complex complementary tests, available in larger urban centers ${ }^{(13)}$. It is suggested, therefore, that access to diagnosis and specialized services can be enjoyed mostly by individuals with better economic conditions.

Although the social, cultural and demographic factors are associated with the prevalence of some diseases, it is noted that the population served by water and sewage networks and with a higher mean per capita income, had a strong correlation with the rates of hospitalization due to IHDs, revealing that developed regions have better health conditions, and hospitalization rates also reflect greater efforts to treat the diseases.

However, hospitalization should not be the only resource in the search for medical assistance; primary health care is a strong ally capable of offering resources for several problems and, in this aspect, the organization of health care networks allows for the articulation between the levels of assistance, focusing on the needs of the population and not on the provision of services ${ }^{(16)}$.

Another important factor, in this case, are hospitalizations for conditions sensitive to Primary Health Care. A study carried out in the state of Paraná showed that most of the consultations carried out in an Emergency Care Unit were due to weaknesses in the provision of care at the primary level, as well as the possibility of a technological and structural apparatus, which facilitates the performance of exams, with delivery of results in less time ${ }^{(17)}$. These data foster the need for a better structuring of PHC to meet the demand, with direct and resolute interventions.

A study conducted in Northeastern Spain associated AMI with younger people with drug abuse, dyslipidemia, current consumption of tobacco and alcohol(18); among these associated variables, for the analysis of Brazil, a correlation was found between the rates of hospitalizations for IHDs and 
alcohol consumption and high cholesterol. This correlation reiterates the importance of the strategies proposed by the World Health Organization (WHO) which, besides aiming at reducing the use of tobacco and alcohol, reinforces the importance of promoting healthy eating and the practice of physical activity in the population, reducing cases of obesity and hypertension, based on the objectives of reducing mortality due to CVDs, cancer and diabetes by $25 \%{ }^{(2)}$.

In this regard, the $\mathrm{WHO}$ also proposes a relative reduction of $30 \%$ in the mean salt intake in the population. It is noteworthy that high salt consumption had a moderate correlation with hospitalizations due to IHDs; on this correlation, it is worth mentioning that 1.65 million deaths worldwide due to cardiovascular diseases were attributed to high sodium consumption, above the reference level. Georgia is the country with the highest rate of cardiovascular deaths attributed to high salt consumption, while Kenya has the lowest rates ${ }^{(19)}$.

In Europe, the country with the highest hospitalization rates for CVDs is Belarus, which had a 27\% increase in hospitalizations compared to the years 2000 and 2013, with other European countries also showing an increase in the hospitalization rates and, when analyzing the hospitalizations due to stroke, 35 of 52 countries registered an increase in hospitalizations for this cause ${ }^{(20)}$.

As limitations of the present study, it is highlighted that the diagnoses of the hospital admissions are not always reliable, since they are subject to classification errors and that, in using ICD-10, with the computerization of the SIH-SUS for the reimbursement of the hospital services, under- or overestimation of the CVD diagnoses may occur. However, the use of the database makes it possible to carry out studies with reduced costs and also easy access, even so, there is a need to intensify the computerization and training of the personnel for the correct filling in of the hospitalization authorizations, in order to minimize the biases that occur in these databases.

\section{Q CONCLUSION}

When related to the global mean and to the search for potentially explanatory factors of the incidence differentials found, the studies with spatial methodologies, intrinsic to the identification of regions at risk, make this research extremely important for the advancement of science. This study showed that all the Brazilian regions showed a reduction in the hospitalization rates due to CVDs. However, when comparing IHDs and CbVDs, the Southern region showed higher hospitalization rates. As for the sociodemographic variables, CVDs, IHDs and CbVDs showed a strong correlation with schooling and with an active sewage service, and a negative correlation with the Gini's index. In the clinical variables, the same morbidities analyzed showed a significant correlation with arterial hypertension, salt consumption and high cholesterol and consumption of alcohol, use of tobacco and its by-products.

It is suggested to develop more studies that deal with CVDs with the use of spatial distribution and autocorrelation, for a better visualization of the health conditions in the population and knowledge of the most prevalent diseases, in addition to checking where they occur the most, potentiating the action of the health care professionals more effectively in the needs of the population.

Hospitalizations are valuable indicators to know the main diseases and their problems in the population and, although most of the studies use the outcome of death to work epidemiologically on the distribution of these diseases, hospitalizations reflect beyond the prevalence, where the greatest concentration is the number of visits in view of the complications, suggesting the need for greater efforts to reduce the burden of diseases with preventive interventions.

Finally, when considering the discrepancy between the results in the regions, it is also suggested that there may be an underreporting in some locations, a computerized system needs to be rigorously and carefully filled out so that notifications faults do not occur. In addition, the results by regions can support new intervention methodologies aimed at the quality of life of the population, as well as a better access to the health services.

\section{REFERENCES}

1. Devaux M, Lerouge A, Ventelou B, Goryakin Y, Feigl A, Vuik S, et al. Assessing the potential outcomes of achieving the World Health Organization global non-communicable diseases targets for risk factors by 2025 : is there also an economic dividend? Public Health 2019;169:173-9. doi: https://doi.org/ 10.1016/j.puhe.2019.02.009

2. Ministry of Health (BR). Departamento de Informática do SUS - DATASUS. Informações de saúde.Epidemiológicas e morbidade. Brasília, 2017 [cited 2017 Dec 27]. Available from: http://datasus.saude.gov.br/epidemiologicase-morbidade/

3. World Health Organization (CH). Global status report on noncommunicable diseases 2014: attaining the nine global noncommunicable diseases targets; a shared responsibility. Geneva: World Health Organization; 2014 [cited 2017 Dec 27]. Available from: https://apps.who.int/iris/bitstream/ handle/10665/148114/9789241564854_eng.pdf;jsessionid=2477E16 1A282185E1978DE908AF83E98? sequence $=1$

4. Siqueira ASE, Siqueira-Filho AG, Land MGP. Analysis of the economic impact of cardiovascular diseases in the last five years in Brazil. Arq Bras Cardiol. 2017 [cited 2017 Dec 27];109(1):39-46. Available from: http://www.scielo.br/scielo. php?pid=S0066-782X2017000700039\&script=sci_arttext 
5. Malta DC, Campos M0, Oliveira MM de, Iser BPM, Bernal RTI, Claro RM, et al. Prevalência de fatores de risco e proteção para doenças crônicas não transmissíveis emadultos residentes em capitais brasileiras, 2013. Epidemiol Serv Saúde. 2015;23(4):387-73. doi: https://doi.org/10.5123/S1679-49742014 000400003

6. Teston EF, Cecilio HPM, Santos AL, Arruda GO, Radovanovic CAT, MarconSS. Factors associated with cardiovascular diseases in adults. Medicina (Ribeirao Preto) 2016;49(2):95-102. doi: https://doi.org/10.11606/issn.2176-7262.v49i2p95102

7. Figueiredo FSF, Oliveira RR, Sanches RDCN, Matias TAF, Radovanovic CAT. Mortalidade por doenças cardiovasculares no estado do Paraná. Cogitare Enferm. 2018;23(4):e56973. doi: https://doi.org/10.5380/ce.v23i4.56973

8. Alves JED, Cavenaghi SM, Barros LFW, Carvalho AA. Distribuição espacial da transição religiosa no Brasil. Tempo Soc 2017;29(2):215-42. doi: https://doi. org/10.11606/0103-2070.ts.2017.112180

9. Hulley SB, Duncan MS, Schmidt MI, Duncan BB. Delineando a pesquisa clínica: uma abordagem epidemiológica. Porto Alegre: Artmed; 2008.

10. Andrade SSA, Stopa SR, Brito AS, Chueri PS, Szwarcwald CL, Malta DC. Prevalência de hipertensão arterial autorreferida na população brasileira: análise da Pesquisa Nacional de Saúde, 2013. Epidemiol Serv Saúde 2015 [cited 2017 Dec 27];24(2):297-304. Available from: https://www.scielosp.org/article/ ress/2015.v24n2/297-304/pt/

11. Figueiredo FSF. Análise das internações hospitalares por doenças cardiovasculares em adultos no Brasil [dissertação]. Maringá (PR): Universidade Estadual de Maringá; 2018.

12. Cunha e Silva DC, Lourenço RW, Cordeiro RC, Cordeiro MRD. Análise da relação entre a distribuição espacial das morbidades por obesidade e hipertensão arterial para o estado de São Paulo, Brasil, de 2000 a 2010. Ciênc Saúde Coletiva 2014;19(6):1709-19. doi: https://doi. org/10.1590/1413-81232014196.15002013
13. Park S-Y, Kwak J-M, Seo E-W, Lee K-S. Spatial analysis of the regional variation of hypertensive disease mortality and its socio-economic correlates in South Korea. Geospat Health 2016;11:420. doi: https://doi.org/10.4081/gh.2016.420

14. Baptista EA, Queiroz BL. Spatial analysis of mortality by cardiovascular disease in the adult population: a study for Brazilian micro-regions between 1996 and 2015. Spat Demogr 2019;7(1):83-101. doi: https://doi.org/10.1007/s40980-019-00050-6

15. Rosengren A, Smyth A, Rangarajan S, Ramasundarahettige C, Bangdivala SI, AlHabib KF, et al. Socioeconomic status and risk of cardiovascular disease in 20 low-income, middle-income, and high-income countries: the Prospective Urban Rural Epidemiologic (PURE) study. Lancet Glob Health 2019; 7(6):e748-e760. doi: https://doi.org/10.1016/S2214-109X(19)30045-2

16. Mendes EV. A construção social da Atenção Primária à Saúde . Brasília (DF): Conass; 2015.

17. Rêgo AS, Rissardo LK, Scolari GAS, Sanches RCN, Carreira L, Radovanovic CAT. Factors associated with the care of elderly persons with primary health care sensitive conditions. Rev Bras Geriatr Gerontol 2017;20(6):773-84. doi: https:// doi.org/10.1590/1981-22562017020.170120

18. AbedMA, EshahNF,MoserDK. Risk profile ofmyocardial infarction inyoung versus older adults. Heart Lung 2018;47(3):226-30. doi: https://doi.org/10.1016/ j.hrtlng.2018.03.002

19. Mozaffarian D, Fahimi S, Singh GM, Micha R, Khatibzadeh S, Engell RE, et al. Global sodium consumption and death from cardiovascular causes. N Engl J Med 2014;371(7):624-34. doi: https://doi.org/10.1056/NEJMoa1304127

20. Townsend N, Wilson L, Bhatnagar P, Wickramasinghe K, Rayner M, Nichols M. Cardiovascular disease in Europe: epidemiological update 2016. Eur Heart J. 2016;37(42):3232-45. doi: https://doi.org/10.1093/eurheartj/ehw334

\section{Funding:}

Coordination for the Improvement of Higher-Level Personnel (Coordenação de Aperfeiçoamento de Pessoal de Nível Superior, (APES), Brazil.

\section{- Corresponding author:}

Anderson da Silva Rêgo

E-mail: Anderson.dsre@hotmail.com

\section{Associate editor:}

